University of Wollongong

Research Online

Faculty of Business - Papers (Archive)

Faculty of Business and Law

$1-1-2013$

Different metabolic responses during incremental exercise assessed by localized 31P MRS in sprint and endurance athletes and untrained individuals

Dominik Pesta

University of Innsbruck

V Paschke

University of Innsbruck

Florian Hoppel

University of Innsbruck

Conrad Kobel

University of Wollongong, ckobel@uow.edu.au

Christian Kremser

Medical University Innsbruck

See next page for additional authors

Follow this and additional works at: https://ro.uow.edu.au/buspapers

Research Online is the open access institutional repository for the University of Wollongong. For further information contact the UOW Library: research-pubs@uow.edu.au 


\title{
Different metabolic responses during incremental exercise assessed by localized 31P MRS in sprint and endurance athletes and untrained individuals
}

\begin{abstract}
Until recently, assessment of muscle metabolism was only possible by invasive sampling. 31P magnetic resonance spectroscopy (31P MRS) offers a way to study muscle metabolism non-invasively. The aim of the present study was to use spatially-resolved 31P MRS to assess the metabolism of the quadriceps muscle in sprint-trained, endurance-trained and untrained individuals during exercise and recovery. 5 sprint-trained (STA), 5 endurance-trained (ETA) and 7 untrained individuals (UTI) completed one unlocalized 31P MRS session to measure phosphocreatine $(\mathrm{PCr})$ recovery, and a second session in which spatially-resolved 31P MR spectra were obtained. $P C r$ recovery time constant $(\tau)$ was significantly longer in STA ( $50 \pm 17 \mathrm{~s})$ and UTI $(41 \pm 9 \mathrm{~s})$ than in ETA $(30 \pm 4 \mathrm{~s}),(\mathrm{P}<0.05)$. PCr changes during exercise differed between the groups, but were uniform across the different components of the quadriceps within each group. pH during recovery was higher for the ETA than for the UTI $(P<0.05)$ and also higher than for the STA $(P<0.01)$. Muscle volume was greater in STA than in UTI $(P<0.05)$ but not different from ETA. Dynamic 31P MRS revealed considerable differences among endurance and sprint athletes and untrained people. This non-invasive method offers a way to quantify differences between individual muscles and muscle components in athletes compared to untrained individuals. 2013 Georg Thieme Verlag KG Stuttgart.New York.
\end{abstract}

\section{Keywords}

different, 31p, metabolic, mrs, sprint, endurance, athletes, untrained, individuals, responses, during, incremental, exercise, assessed, localized

\section{Publication Details}

Pesta, D., Paschke, V., Hoppel, F., Kobel, C., Kremser, C., Esterhammer, R., Burtscher, M., Kemp, G. J. \& Schocke, M. (2013). Different metabolic responses during incremental exercise assessed by localized 31P MRS in sprint and endurance athletes and untrained individuals. International Journal of Sports Medicine, 34 (8), 669-675.

\section{Authors}

Dominik Pesta, V Paschke, Florian Hoppel, Conrad Kobel, Christian Kremser, R Esterhammer, Martin Burtscher, Graham J. Kemp, and Michael Schocke 


\section{Different Metabolic Responses during Incremental Exercise Assessed by Localized P- 31 MRS in Sprint and Endurance Athletes and Untrained Individuals}

ARTICLE in INTERNATIONAL JOURNAL OF SPORTS MEDICINE · FEBRUARY 2013

Impact Factor: $2.07 \cdot$ DOI: 10.1055/s-0032-1327648 · Source: PubMed

CITATIONS

4

9 AUTHORS, INCLUDING:

Christian Kremser

Medizinische Universität Innsbruck

224 PUBLICATIONS 3,664 CITATIONS

SEE PROFILE

\section{Graham J Kemp}

University of Liverpool

374 PUBLICATIONS $\quad 6,589$ CITATIONS

SEE PROFILE
Regina Esterhammer

Medizinische Universität Innsbruck

51 PUBLICATIONS $\quad 1,164$ CITATIONS

SEE PROFILE

Michael Schocke

Medizinische Universität Innsbruck

285 PUBLICATIONS $\mathbf{4 , 7 5 6}$ CITATIONS

SEE PROFILE 


\title{
Different Metabolic Responses during Incremental Exercise Assessed by Localized ${ }^{31} \mathrm{P}$ MRS in Sprint and Endurance Athletes and Untrained Individuals
}

\author{
Authors \\ D. Pesta ${ }^{1,2}$, V. Paschke ${ }^{1}$, F. Hoppel ${ }^{2}$, C. Kobel ${ }^{3}$, C. Kremser ${ }^{1}$, R. Esterhammer ${ }^{1}$, M. Burtscher ${ }^{2}$, G. J. Kemp ${ }^{4}$, \\ M. Schocke \\ Affiliations \\ Affiliation addresses are listed at the end of the article
}

\author{
Key words \\ - ${ }^{31}$ P MRS \\ - CSI \\ - PCr recovery \\ - muscle function \\ exercise training
}

accepted after revision September 12, 2012

\section{Bibliography}

DOI http://dx.doi.org/

10.1055/s-0032-1327648

Published online: 2013

Int J Sports Med

(c) Georg Thieme

Verlag KG Stuttgart · New York

ISSN 0172-4622

Correspondence

Dominik Pesta

Department of Radiology

Innsbruck Medical University

Anichstraße 35

6020 Innsbruck

Austria

Tel.: + 43/512/50426219

Fax: $+43 / 512 / 50422758$

dominik.pesta@yale.edu

\section{Abstract \\ $\nabla$}

Until recently, assessment of muscle metabolism was only possible by invasive sampling. ${ }^{31} \mathrm{P}$ magnetic resonance spectroscopy ( ${ }^{31} \mathrm{P}$ MRS) offers a way to study muscle metabolism non-invasively. The aim of the present study was to use spatiallyresolved ${ }^{31} \mathrm{P}$ MRS to assess the metabolism of the quadriceps muscle in sprint-trained, endurancetrained and untrained individuals during exercise and recovery. 5 sprint-trained (STA), 5 endurance-trained (ETA) and 7 untrained individuals (UTI) completed one unlocalized ${ }^{31} \mathrm{P}$ MRS session to measure phosphocreatine $(\mathrm{PCr})$ recovery, and a second session in which spatially-resolved ${ }^{31} \mathrm{P}$ MR spectra were obtained. $\mathrm{PCr}$ recovery time

\section{Introduction}

$\nabla$

Skeletal muscle shows remarkable plasticity in adapting to different exercise training regimes. It is well known that athletes with a background of endurance training have better oxidative metabolism than sprint-trained athletes [34], resulting from cardiovascular adaptations, enhanced capillarity and increased mitochondrial density [25] as a result of training-specific adaptations to highvolume load. In sprint athletes, at the other end of the continuum, increased force-production capacity and buffering capacity support high power output and running speed [38]. According to their demand, muscles of untrained individuals seem to reside between those extremes [46].

It has long been a goal of sports science to characterize performance-related characteristics of single muscles, but until relatively recently this required ex vivo measurements on biopsy specimens. Classification of muscle fibres depends on the technique used. Histochemical analysis of biopsy specimens has been widely employed to characterize fibres into type I and type II accord- constant $(\tau)$ was significantly longer in STA $(50 \pm 17 \mathrm{~s})$ and UTI $(41 \pm 9 \mathrm{~s})$ than in ETA $(30 \pm 4 \mathrm{~s})$, $(\mathrm{P}<0.05)$. $\mathrm{PCr}$ changes during exercise differed between the groups, but were uniform across the different components of the quadriceps within each group. $\mathrm{pH}$ during recovery was higher for the ETA than for the UTI $(\mathrm{P}<0.05)$ and also higher than for the STA $(P<0.01)$. Muscle volume was greater in STA than in UTI $(\mathrm{P}<0.05)$ but not different from ETA. Dynamic ${ }^{31} \mathrm{P}$ MRS revealed considerable differences among endurance and sprint athletes and untrained people. This noninvasive method offers a way to quantify differences between individual muscles and muscle components in athletes compared to untrained individuals.

ing to their ATPase activity. ${ }^{31} \mathrm{P}$ nuclear magnetic resonance spectroscopy ( ${ }^{31} \mathrm{P}$ MRS) has been used to evaluate metabolic properties of skeletal muscle non-invasively. It is well established that ${ }^{31} \mathrm{P}$ MRS measurements of post-exercise phosphocreatine $(\mathrm{PCr})$ recovery (a purely oxidative process) can be used as a measure of muscle mitochondrial oxidative capacity, which correlates well with various in vitro measurements of mitochondrial numbers and function $[15,20,26,30]$.

Dynamic ${ }^{31} \mathrm{P}$ MRS measurements obtained during exercise and recovery using an MR-compatible ergometer have been used to evaluate progress in training [23] and identify differences between differently specialised athletes [28]. Differences between sprinters and long-distance runners have also been detected in PCr/ATP and $\mathrm{PCr} / \mathrm{Pi}$ ratios in resting muscle, which are thought to reflect different fibre-type composition [2]. However, human muscle shows considerable variation in biochemical properties, perfusion, and fibre type composition [19,32]. Most human biopsy data, especially in trained individuals, comes from vastus lateralis or rectus femoris, 


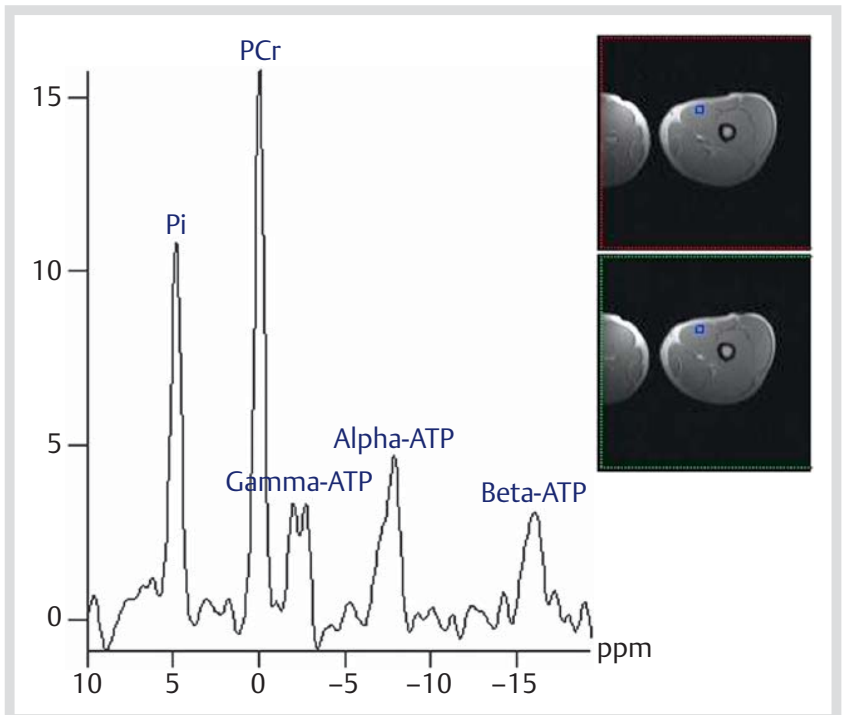

Fig. 1 Localized dynamic ${ }^{31} \mathrm{P}$ spectra of the medialis muscle during exercise.

and much of what is known about other muscles comes from autopsy material $[9,16]$. There is some evidence that fibre-type distribution among different parts of the quadriceps is uniform in untrained subjects [12], at least in vastus lateralis and rectus femoris. The well-known shifts towards type I fibres with endurance training and type II with strength/speed training have been mostly studied in vastus lateralis $[36,44]$. It is not clear, though, whether heterogeneity of skeletal muscle structure, composition, and capillarity results in local differences in metabolic function between different muscle regions in athletes or untrained subjects. ${ }^{31} \mathrm{P}$ MRS can differentiate between the athletes based on their skeletal muscle properties. Whether or not the other muscle groups of the quadriceps follow the same pattern remains unknown. Although findings of differences in $\mathrm{PCr}$ recovery kinetics between sprinters and endurance athletes are not new [18], results are often based on measurements of the bulk of the muscle. We wanted to investigate this in the different component muscles of the quadriceps and also incorporate a group of untrained individuals. In this respect we hypothesised that the metabolic situation in the main locomotor muscle and its component muscles is homogenous within a specific group, but will be different and highly dependent on activity level and training status.

We therefore studied aerobic performance in the muscle of untrained individuals and athletes specializing in the 2 extremes of sprint and long-distance events. Using unlocalized ${ }^{31} \mathrm{P}$ MRS, we took (i) the time constant $(\tau)$ of $\mathrm{PCr}$ resynthesis after submaximal exercise in the quadriceps as an inverse measure of whole-muscle oxidative capacity. We also used ${ }^{31} \mathrm{P}$ chemical shift imaging (CSI) to assess (ii) spatial metabolic variation in different compartments of the quadriceps muscle. The results throw light on the spatial homogeneity of adaptive changes in muscle of a variously active population.

\section{Materials and Methods}

$\nabla$

We studied 7 male untrained individuals and 10 male athletes with $7 \pm 2$ years (mean \pm SD) of national or international competitive experience, who had undergone specific training pro- grams: the sprint-trained group (STA: $n=5$, age $23 \pm 2$ years, height $179 \pm 6 \mathrm{~cm}$, weight $77 \pm 7 \mathrm{~kg}$ ) were sprinters of national and international level with a competitive distance of 100$400 \mathrm{~m}$, while the endurance-trained group (ETA: $n=5$, age $27 \pm 9$ years, height $176 \pm 4 \mathrm{~cm}$, weight $65 \pm 6 \mathrm{~kg}$ ) were endurance athletes of national level, comprising 4 runners with competitive distances $3000-5000 \mathrm{~m}$ and 1 road cyclist. The untrained individuals (UTI: $n=7$, age $30 \pm 5$ years, height $179 \pm 6 \mathrm{~cm}$, weight $77 \pm 7 \mathrm{~kg}$ ) did not engage in any regular physical activity or sport (less than $2 \mathrm{~h}$ activity per week) and were therefore classified as sedentary.

The present study meets the ethical standards of the journal [14] and was approved by the ethics committee of Innsbruck Medical Universtiy (AN3433 271/4.12). After giving written informed consent, subjects performed MR measurements of the quadriceps muscle at the Department of Radiology, Innsbruck Medical University in a $1.5 \mathrm{~T}$ whole-body MR scanner (Magnetom Avanto, Siemens, Erlangen, Germany) using a circular surface coil (Siemens, Erlangen, Germany) double-tuned to ${ }^{1} \mathrm{H}$ at $63.5 \mathrm{MHz}$ and ${ }^{31} \mathrm{P}$ at $25.8 \mathrm{MHz}$. Subjects lay prone in the bore, strapped to the table over upper legs, buttocks and lower back to avoid movement artefacts during measurement. With their non-dominant leg (defined as the leg opposite to that preferred in jumping activities) they performed repetitive dynamic single-leg extensions on an MR-compatible ergometer using a pedal connected to a valve-adjustable air pressure system, controlled by feedback of current power output (Quadspect, Ergospect GmbH, Austria). ${ }^{31} \mathrm{P}$ MRS exercise studies were carried out after at least $24 \mathrm{~h}$ activity break. Subjects attended twice, to first perform an incremental and then a submaximal exercise protocol. In both cases, subjects performed metronome-timed full knee extensions at $0.5 \mathrm{~Hz}$. The incremental exercise protocol started at $4.5 \mathrm{~W}$, increasing by $1.5 \mathrm{~W}$ every $2 \mathrm{~min}$ until exhaustion. After completion, $\mathrm{PCr}$ recovery was monitored for $4 \mathrm{~min}$. Unlocalized ${ }^{31} \mathrm{P}$ free induction decay (FID) sequences (no localization sequence) were acquired throughout 10-scan groups with repetition time (TR) $1000 \mathrm{~ms}$, giving $10 \mathrm{~s}$ time resolution. Subsequently a $\mathrm{T} 1$-weighted spin-echo sequence $(\mathrm{TR}=550 \mathrm{~ms}, \mathrm{TE}=12 \mathrm{~ms})$ was performed which covered both upper legs with 40 slices, with a $320 \mathrm{~mm}$ field of view, $10 \mathrm{~mm}$ slice thickness with $2 \mathrm{~mm}$ interslice gap and a $320 \times 320$ matrix. Muscle volume for each slice was obtained by multiplying measured planimetric areas by the interslice distance, summed for all the slices, and converted to total quadriceps muscle mass assuming a density of $1.056 \mathrm{~g} / \mathrm{ml}$. In the second session, subjects performed submaximal exercise at $80 \%$ of the maximal power output from the first session. Spatially-resolved spectra were acquired every $2 \mathrm{~min}$ from the portion of quadriceps that was covered by the coil as determined by a localizer matched to the first session. After 2 min rest (baseline measurement) the protocol consisted of 2 exercise increments (E1 and E2) and 2 measurements during recovery (R1 and R2). A chemical shift imaging (CSI) spin echo sequence was used, with $\mathrm{TR}=790 \mathrm{~ms}$, TE $=2.3 \mathrm{~ms}$, field of view $200 \times 200 \mathrm{~mm}^{2}$ with weighted phase encoding $(8 \times 8$ phase-encoding steps $)$ and a slice thickness of $80 \mathrm{~mm}$, giving a time resolution of $2 \mathrm{~min}$ with voxel size $50 \mathrm{~cm}^{3}$. PCr signal to noise ratio values for the different muscle groups were ca. 15 (7.5/0.5 for the medials muscle at baseline, see $\bullet$ Fig. 1).

Spectral data were processed with the commercial software package LUISE (Siemens, Erlangen, Germany). Baseline correction was performed semi-automatically by setting the peak ranges of inorganic phosphate $(\mathrm{Pi})$ and $\mathrm{PCr}$ as references, and 
phase correction was applied semi-automatically using 12 iterations with $\mathrm{Pi}$ and $\mathrm{PCr}$ as reference peaks; supplementary manual phase- or baseline correction was performed if necessary. The peak areas and peak positions of $\mathrm{PCr}$ and Pi were fitted in the frequency domain. Concentrations of $\mathrm{Pi}$ and $\mathrm{PCr}$ during rest were estimated from signal ratios to ATP, corrected for NOE and T1 saturation effects $[3,20]$. Intracellular concentrations of $\mathrm{PCr}$ and $\mathrm{Pi}$ were calculated relative to $\beta$-ATP, assuming a resting $\beta$-ATP concentration of $8.2 \mathrm{mmol}^{-1} \mathrm{~L}^{-1}$ and corrected for magnetic saturation [21]. For kinetic analysis, $\mathrm{PCr}$ changes were expressed relative to baseline values, and $\mathrm{PCr}$ recovery was fitted to a monoexponential curve to determine $\tau$. Intracellular $\mathrm{pH}$ was calculated from the chemical shift of $\mathrm{Pi}$ relative to $\mathrm{PCr}(\delta)$ as $\mathrm{pH}=6.75+\log (\delta-3.27) /(5.69-\delta)[33]$.

Statistical analysis was carried out using $\mathrm{R}$ software, version 2.15.1 [37]. Descriptive statistics are given as mean and standard deviation. To answer the first question, whether the PCr recovery

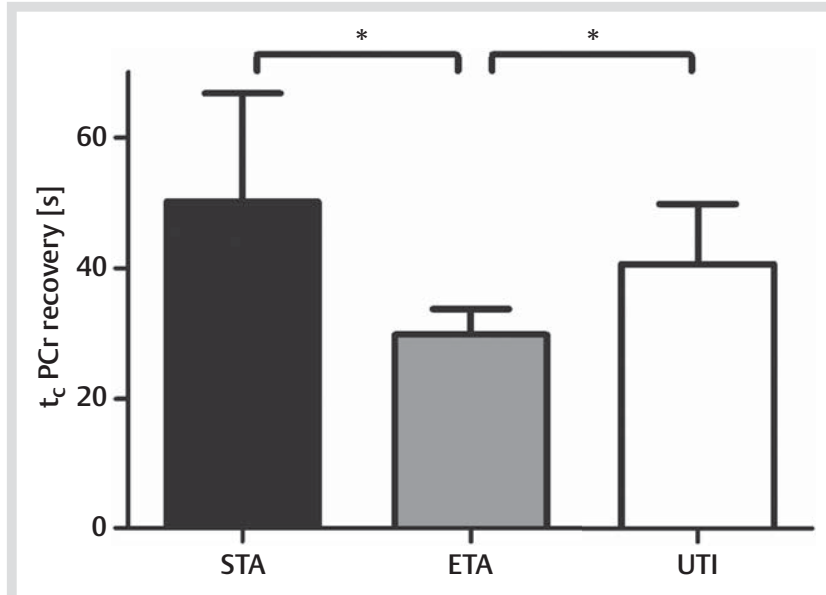

Fig. 2 Mean $\pm S D$ of $\mathrm{PCr}$ recovery time derived from unlocalised spectra of the quadriceps for STA (black), ETA (grey) and UTI (white). * denotes significant differences between the groups at the 0.05 level. time would be different between the 3 groups, we applied oneway analysis of variance (ANOVA). For the second set of questions, whether the 3 groups of athletes/individuals and whether the component of the quadriceps responded differently to the exercises, we applied two-way ANOVAs (between and within design) separately for each component muscle and separately for each group, respectively. The significance level was set to 0.05 . Post-hoc analyses were performed using pairwise t-tests without correction for multiple testing due to the exploratory character of the study.

\section{Results}

$\mathrm{PCr}$ recovery $\tau$ of the 3 training groups was significantly different (ANOVA; $\mathrm{P}<0.05)$. It was shortest in the ETA $(30 \pm 4 \mathrm{~s})$ and longest in STA $(50 \pm 17 \mathrm{~s})$, while the UTI $(41 \pm 9 \mathrm{~s})$ was in the middle. Posthoc comparisons revealed that the values of the STA and the UTI differed significantly $(\mathrm{P}<0.05)$ from the ETA with respect to a slower recovery in these groups ( $\bullet$ Fig. 2 ).

This is consistent with the spatially-resolved data, which show an average decline of the component muscles during E1 and E2 in the ETA of 60 and $58 \%$ compared to the UTI (38 and 24\%) and STA (55 and 35\%) from baseline, respectively ( $\bullet$ Fig. 3). During $\mathrm{R} 1$ and $\mathrm{R} 2, \mathrm{PCr}$ recovered fastest and almost completely to 92 and $99 \%$ in the ETA compared to 68 and $82 \%$ in the UTI and slowest to only 49 and $76 \%$ in the STA, respectively. There was no significant difference in $\mathrm{PCr}$ depletion between the different component muscles within each group (right panel of $\odot$ Fig. 3). - Fig. 3 depicts the change of $\mathrm{PCr}$ for each training group separately for each compartment of the quadriceps. Details about means and standard errors are given in $\bullet$ Table $\mathbf{1 .}$

Analysis of variance showed highly significant time and interaction effects (ANOVA; P<0.01) for each component muscle. The group effect was highly significant in intermedius and significant in lateralis and medialis, respectively (ANOVA; $\mathrm{P}<0.01$ and $\mathrm{P}<0.05)$. However, this effect could not be found in the rectus.

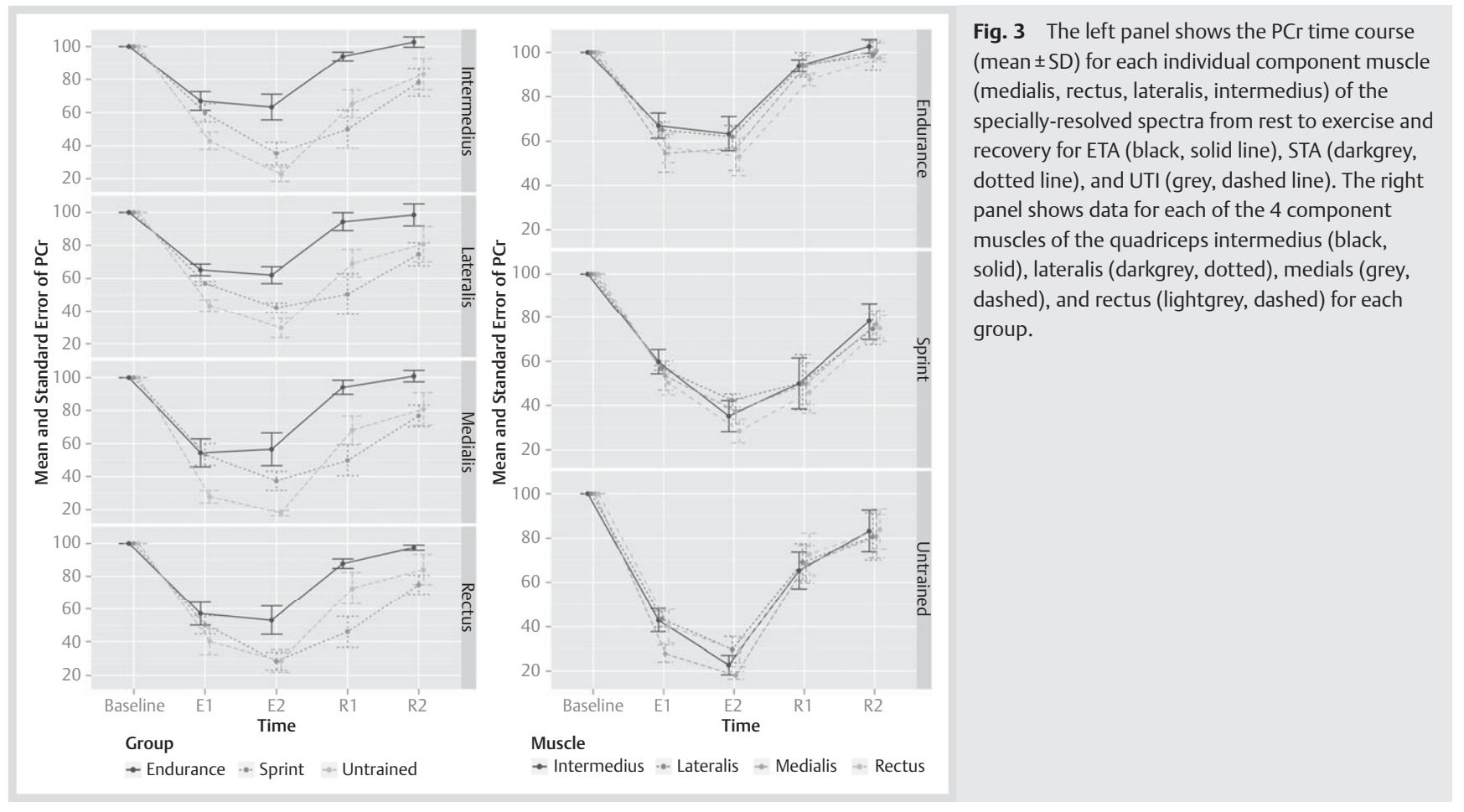




\begin{tabular}{|c|c|c|c|c|c|c|}
\hline \multicolumn{7}{|c|}{$\mathrm{PCr}$} \\
\hline Muscle & Group & Baseline & E1 & E2 & R1 & R2 \\
\hline \multirow[t]{3}{*}{ intermedius } & ETA & $100.0(0.0)$ & $67.0(11.3)$ & $63.3(15.5)$ & $93.9(5.2)$ & $102.6(6.2)$ \\
\hline & STA & $100.0(0.0)$ & $59.8(12.2)$ & $35.2(15.6)$ & $50.0(25.7)$ & $78.2(18.7)$ \\
\hline & UTI & $100.0(0.0)$ & $42.9(14.1)$ & $22.6(11.5)$ & $65.3(22)$ & $83.2(25)$ \\
\hline \multirow[t]{3}{*}{ lateralis } & ETA & $100.0(0.0)$ & $65.2(7.1)$ & $62.0(10.2)$ & $94.3(11.1)$ & $98.5(13.3)$ \\
\hline & STA & $100.0(0.0)$ & $57.0(2.4)$ & $42.2(6.6)$ & $50.5(27.9)$ & 74.5 (15.6) \\
\hline & UTI & $100.0(0.0)$ & $43.5(9.4)$ & $29.6(15.5)$ & $69.1(22.2)$ & $80.8(28.3)$ \\
\hline \multirow[t]{3}{*}{ medialis } & ETA & $100.0(0.0)$ & $54.4(16.9)$ & $56.6(19.8)$ & 94.1 (8.7) & $100.9(6.8)$ \\
\hline & STA & $100.0(0.0)$ & $53.5(14.8)$ & $37.3(12.8)$ & $49.8(21.1)$ & 76.7 (14.6) \\
\hline & UTI & $100.0(0.0)$ & $27.8(10.1)$ & $18.0(4.5)$ & $68.2(22.4)$ & $80.8(25.8)$ \\
\hline \multirow[t]{3}{*}{ rectus } & ETA & $100.0(0.0)$ & $57.1(13.7)$ & $53.0(17.3)$ & $87.6(5.7)$ & $97.4(3.2)$ \\
\hline & STA & $100.0(0.0)$ & $50.2(12.4)$ & 28.5 (11.9) & $45.9(21.1)$ & 74.8 (12.9) \\
\hline & UTI & $100.0(0.0)$ & $40.1(20.4)$ & $28.6(17.8)$ & $72.7(25.5)$ & $84.0(24.1)$ \\
\hline \multicolumn{7}{|c|}{$\mathrm{pH}$} \\
\hline Muscle & Group & Baseline & E1 & E2 & R1 & R2 \\
\hline \multirow[t]{3}{*}{ intermedius } & ETA & $6.97(0.04)$ & $6.99(0.03)$ & $6.98(0.06)$ & $6.99(0.10)$ & $6.96(0.05)$ \\
\hline & STA & $7.02(0.04)$ & $6.95(0.01)$ & $6.9(0.030)$ & $6.86(0.04)$ & $6.87(0.05)$ \\
\hline & UTI & $7.04(0.05)$ & $6.99(0.04)$ & $6.88(0.05)$ & $6.90(0.12)$ & $7.02(0.13)$ \\
\hline \multirow[t]{3}{*}{ lateralis } & ETA & $7.04(0.08)$ & $7.03(0.03)$ & $7.02(0.02)$ & $6.95(0.09)$ & $6.95(0.04)$ \\
\hline & STA & $7.03(0.05)$ & $7.01(0.03)$ & $6.98(0.02)$ & $6.92(0.11)$ & $6.88(0.08)$ \\
\hline & UTI & $7.09(0.06)$ & $7.05(0.02)$ & $6.95(0.08)$ & $6.98(0.14)$ & $7.08(0.14)$ \\
\hline \multirow[t]{3}{*}{ medialis } & ETA & $7.03(0.07)$ & $7.01(0.05)$ & $6.98(0.02)$ & $6.92(0.05)$ & $7.01(0.09)$ \\
\hline & STA & $7.03(0.08)$ & $7.00(0.04)$ & $6.93(0.07)$ & $6.87(0.06)$ & $6.89(0.10)$ \\
\hline & UTI & $7.07(0.07)$ & $6.99(0.05)$ & $6.90(0.09)$ & $6.90(0.05)$ & $6.98(0.05)$ \\
\hline \multirow[t]{3}{*}{ rectus } & ETA & $7.00(0.04)$ & $7.01(0.03)$ & $6.98(0.04)$ & $6.90(0.10)$ & $6.97(0.04)$ \\
\hline & STA & $7.11(0.06)$ & $6.99(0.02)$ & $6.87(0.07)$ & $6.80(0.06)$ & $6.80(0.06)$ \\
\hline & UTI & $7.06(0.06)$ & $7.02(0.04)$ & $6.88(0.04)$ & $6.87(0.08)$ & $6.97(0.07)$ \\
\hline
\end{tabular}

Table 1 Means and standard deviation are given for $\mathrm{PCr}$ (upper panel) and $\mathrm{pH}$ (lower panel) for every component muscle and every group over the time course of the exercise test, E-exercise; E-recovery.
Post-hoc tests showed that the ETA had higher values than the STA during recovery in all quadriceps compartments (R1, $\mathrm{P}<0.01 ; \mathrm{R} 2, \mathrm{P}<0.05)$. Also during E2 the values were higher in the intermedius $(\mathrm{P}<0.01)$ and rectus $(\mathrm{P}<0.05)$.

Additionally, the ETA maintained higher relative $\mathrm{PCr}$ concentrations than the UTI at all times for the intermedius and medialis (E1, P<0.01; E2, P<0.01; R1, P<0.01; R2, P<0.05). Except for R2, this was also the case in lateralis, while in rectus there was only a difference at E2.

Except for the intermedius, $\mathrm{PCr}$ was higher in the UTI than in the STA at R1 $(\mathrm{P}<0.05)$. Furthermore, during exercise, $\mathrm{PCr}$ in the medialis was higher in the UTI than the STA $(\mathrm{E} 1, \mathrm{P}<0.01$; E2, $\mathrm{P}<0.05$ ).

- Fig. 4 shows pH for the 3 groups for each quadriceps component muscle. Details about means and standard deviations are given in Table 1. The $\mathrm{pH}$ data reveal significant differences between training groups. When analysing the $\mathrm{pH}$ values of the 3 groups (separately for each quadriceps muscle) we find that there is a highly significant time effect for all compartments (ANOVA; $\mathrm{P}<0.01$ ), while a significant group effect can only be found for rectus (ANOVA; $P<0.05$ ). The interaction effect was highly significant in intermedius and rectus (ANOVA; $\mathrm{P}<0.01$ ) and significant in lateralis (ANOVA; $\mathrm{P}<0.05$ ).

Subsequent posthoc tests showed that $\mathrm{pH}$ for the ETA was higher than for the UTI at E2 and R1 $(\mathrm{P}<0.05)$ and also higher than for the STA at R1 $(\mathrm{P}<0.01)$. At R2, pH for the STA was much lower than for the UTI $(\mathrm{P}<0.01)$. At R2, the UTI showed a higher $\mathrm{pH}$ than the ETA $(P<0.05)$ and the STA $(P<0.01)$ in lateralis. In rectus, $\mathrm{pH}$ for the STA $(\mathrm{P}<0.01)$ was higher than for the ETA at baseline and lower than the ETA at E2 $(\mathrm{P}<0.01), \mathrm{R} 1(\mathrm{P}<0.05)$ and R2 $(\mathrm{P}<0.01) . \mathrm{pH}$ in the STA was also lower than for the UTI during recovery $(\mathrm{R} 1, \mathrm{P}<0.05 ; \mathrm{R} 2, \mathrm{P}<0.01)$.
The right panel of $\odot$ Fig. 3, 4 depicts changes of $\mathrm{PCr}$ and $\mathrm{pH}$ for the 4 compartment muscles of the quadriceps at the 5 time points, separately for each training group. Analysis of variance for $\mathrm{PCr}$ revealed that there is a significant time effect for all training groups (ANOVA; $\mathrm{P}<0.01$ ). No significant group or interaction effect could be found. Similarly for $\mathrm{pH}$, only time was significant (ANOVA; $\mathrm{P}<0.01$ ) for all 3 groups. In addition, in the STA group a significant interaction effect could be observed (ANOVA; $\mathrm{P}<0.01$ ), showing different changes in the compartments over the course of time. No Post-hoc tests were performed.

Muscle volume calculated from 40 slices of the quadriceps muscle of one leg was $2866 \pm 339 \mathrm{~cm}^{3}$ and $2066 \pm 179 \mathrm{~cm}^{3}$ for the STA and the UTI, respectively $(\mathrm{P}<0.05)$ but not different from ETA $\left(2406 \pm 250 \mathrm{~cm}^{3}\right)$.

No significant differences in resting concentrations of $\mathrm{Pi}$ and $\mathrm{PCr}$ were found among STA (PCr: $43 \pm 12$; Pi: $4.7 \pm 1.8 \mathrm{mmol}^{-1} \mathrm{~L}^{-1}$ ), ETA (PCr: 40.0 \pm 8.5 ; Pi: $4.7 \pm 1.6 \mathrm{mmol}_{\mathrm{L}} \mathrm{L}^{-1}$ ) and UTI (PCr: 45.0 \pm 2.3 ; Pi: $\left.4.4 \pm 0.9 \mathrm{mmol} . \mathrm{L}^{-1}\right)$. The absolute values of $\mathrm{PCr}$ at the end of exercise, however, are lowest in the STA $\left(17.4 \pm 5.1 \mathrm{mmol} . \mathrm{L}^{-1}\right)$ and significantly $(\mathrm{P}<0.05)$ different from end-exercise values of the ETA $\left(25.4 \pm 2.6 \mathrm{mmol} . \mathrm{L}^{-1}\right)$. The UTI $\left(22.5 \pm 5.7 \mathrm{mmol} . \mathrm{L}^{-1}\right)$ did not differ from ETA and STA, respectively.

\section{Discussion}

$\nabla$

To our knowledge, this is the first study to assess muscle metabolism by dynamic spatially-resolved ${ }^{31} \mathrm{P}$ MRS in sprint- and endurance-trained athletes and untrained subjects, representing, next to the untrained state, 2 extremes of muscular adaption, and to ask whether heterogeneity of skeletal muscle results in local metabolic differences between different regions (rectus, medialis, lateralis, intermedius) of the quadriceps. The main dif- 


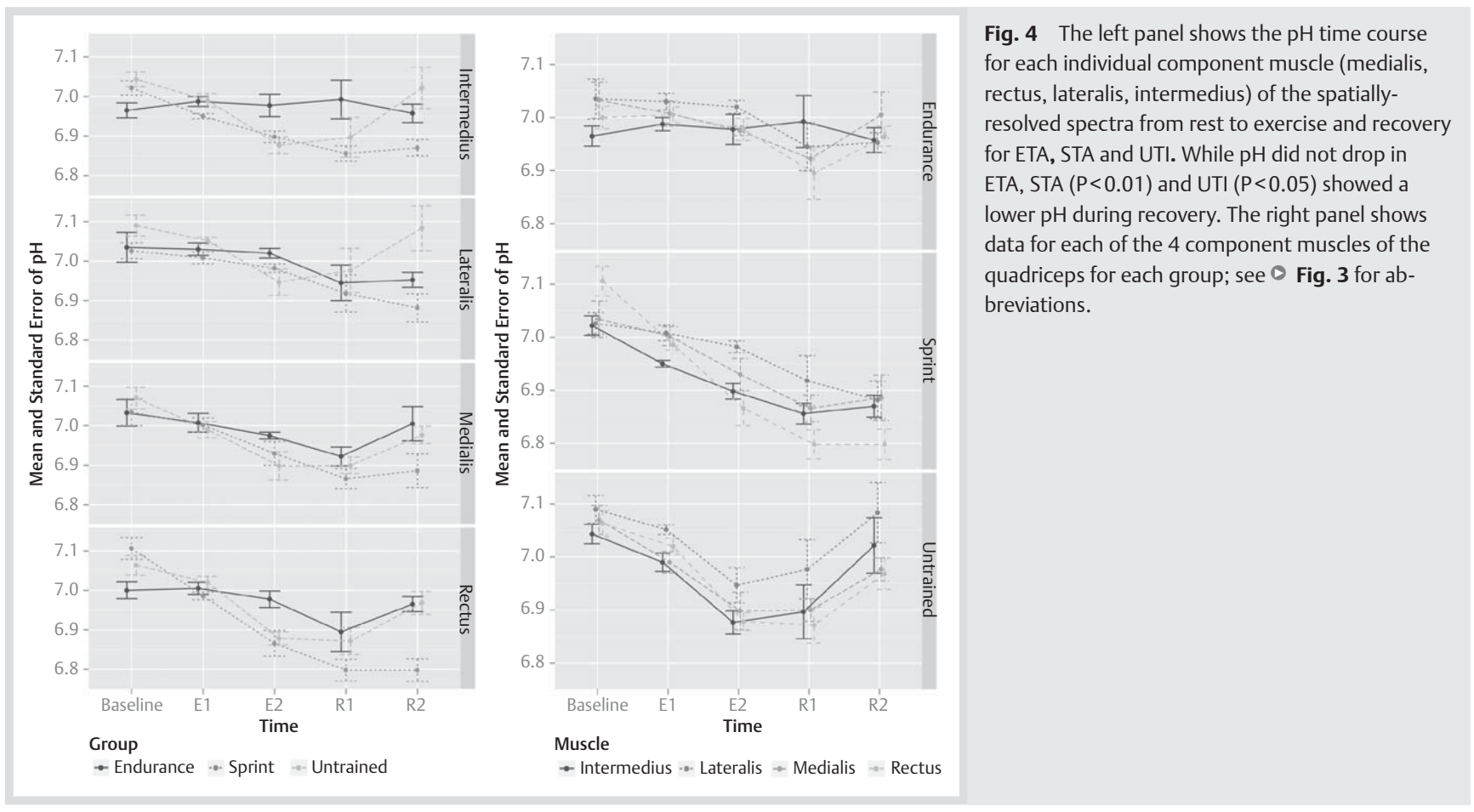

ferences among the groups were the smaller $\mathrm{pH}$ changes and $\mathrm{PCr}$ changes during exercise, and $40 \%$ faster $\mathrm{PCr}$ recovery in ETA compared to the STA and UTI. The exercise differences probably reflect higher contractile costs in STA and UTI, and lower capacity for oxidative $\mathrm{PCr}$ recovery within the exercise-recovery protocol used here.

$\mathrm{PCr}$ recovery kinetics mainly reflect mitochondrial function, and when there is no significant drop in pH or ATP [22,29], as in our experiments, $\mathrm{PCr}$ recovery follows first-order exponential kinetics and $\tau$ is independent of exercise intensity and end-exercise $\mathrm{PCr}$ [45]. Our findings therefore indicate differences in functional mitochondrial performance between STA and ETA compared to UTI and since $\mathrm{O}_{2}$ supply is non-limiting after exercise in normal volunteers, $\mathrm{PCr}$ recovery should reflect mainly intrinsic mitochondrial enzyme function and mitochondrial numbers [13]. It is well established that endurance athletes with a history of low volume training and speed athletes with a history of mainly high-intensity strength and speed training show distinct patterns of muscle enzyme activities [8] whereas untrained people, according to their demand, possess an approximately uniformly distributed muscle fibre spectrum [46]. Our finding of $\sim 40 \%$ higher oxidative capacity in ETA is in agreement with Crowther [6] who reported $\sim 50 \%$ higher oxidative capacity and with Costill [4] who reported $\sim 40 \%$ higher SDH activity in distance runners. However, we did not observe a difference as large as the 2.1-fold difference in $\tau$ between sprinters and distance runners reported by McCully [31]. This might be related to performance-related differences in the populations studied. The $\tau$ reported by Takahashi [42] following moderate intensity exercise in untrained controls ( $41 \pm 3 \mathrm{~s})$ as well as in runners $(34 \pm 2 \mathrm{~s}$ ) is well in the range of our findings for the UTI ( $40 \pm 9 \mathrm{~s})$ and the ETA ( $30 \pm 4 \mathrm{~s}$ ), respectively. However, $\tau$ increased when subjects from [42] were exposed to more severe exercise, being influenced by a significant $\mathrm{pH}$ drop.

Our ETA subjects were able to maintain $\mathrm{PCr}$ during exercise, their high oxidative capacity allowing them to reach a $\mathrm{PCr}$ steady state after only 2 min exercise. Indeed, one subject, at the time of the study a semi-professional cyclist who is now participating in the Tour de France as a professional, achieved partial PCr recovery in the second increment of exercise. This might be related to the variation of motor units activated in these athletes, which helps to spread the work load across the pool of motor units and hence reduce the requirements on a given motor unit. This selective recruitment of motor units by the central nervous system has been observed during submaximal exercise [10].

In the STA subjects, $\mathrm{PCr}$ kinetics during exercise behaved quite differently. In contrast to the purely oxidative kinetics of $\mathrm{PCr}$ recovery, $\mathrm{PCr}$ changes during exercise reflect both mitochondrial function [7] and anaerobic metabolism. It is evident from the submaximal exercise session that STA as well as UTI showed a progressive PCr depletion. In contrast to the STA, the UTI as well as the ETA showed a rather quick recovery of $\mathrm{PCr}$ after cessation of exercise. Recovery, however, was clearly delayed in the STA. The absolute values of $\mathrm{PCr}$ depletion at the end of exercise also reflect the markedly different situation in the muscles of the 3 groups. This is in line with the concept of delayed onset of oxidative phosphorylation due to marked PCr hydrolysis [11].

This major difference between STA, ETA and UTI therefore probably reflects fundamental differences in muscle phenotype. However, it is not known whether skeletal muscle remodelling to a homogenous metabolic phenotype is characteristic in response to a long training process or whether genetic endowment might be the reason for a uniform musculature in these high-performance athletes.

In some subjects we observed an increase of $\mathrm{PCr}$ concentration above the resting level after termination of exercise. This overshoot was most pronounced in 2 subjects from the STA (recovery to 112 and $111 \%$ ). A moderate overshoot was observed in one subject from the ETA (106\%), whereas it was absent in the UTI. The PCr recovery overshoot is well known and related to stressing factors such as greater acidification of muscle cells [47] which is in line with our observations of a pronounced $\mathrm{pH}$ decline in the STA (right panel of $\bullet$ Fig. 4). The reason might be a slow decay during recovery of the direct activation of oxidative 
phosphorylation during muscle work [24]. The reason for the slight increase in $\mathrm{pH}$ at the end of exercise is unclear. We speculate that the exercise induced acidosis might be followed by an augmented ventilatory demand causing a slight respiratory alkalosis upon cessation of exercise in the UTI.

Muscles adapt to training by changing fibre type distribution [35]. Adaptations to endurance training include increased oxidative enzyme activities and mitochondrial density. In contrast, strength training reduces mitochondrial density [43], and sprint-trained athletes predominantly express fast type IIA and IIX fibres, which have lower mitochondrial enzyme activities than type I fibres [27], higher force, and preference for the glycolytic pathway. Consequently, although type II fibres, especially type IIA fibres, can contain many mitochondria, even if the absolute number of mitochondria is unchanged by strength training, as fibres enlarge these are 'diluted' as the cytoplasmic volume per myonucleus (myonuclear domain) increases, especially in fibres expressing fast MHC [39]. This is reflected in reduced activity of oxidative enzymes relative to protein content. Endurance athletes show metabolic adaptations and higher mitochondrial capacity related to specific long-term training which distinguish them from sprint- and strength-trained athletes $[1,17]$. Further, the cardiovascular system of sprint-trained athletes is less developed than that of endurance-trained athletes. Metabolic differences between these 2 groups have also recently been shown during blood flow restriction [41]. Their faster $\mathrm{PCr}$ recovery kinetics are in this sense a system property.

Data on the fibre composition in different muscles of the same subject are scarce. Autopsy data indicate $50 / 50 \%$ type I and II fibres in vastus lateralis and rectus femoris [9]. Biopsy studies in untrained subjects suggest $50 \%$ type I fibre content in vastus lateralis [40]. No data are available on intermedius and vastus medialis. The published data on adaptation to training is derived from biopsy analysis of vastus lateralis [44]. We found that different muscle groups of the quadriceps showed a similar metabolic behaviour, which supports the notion that the quadriceps constitutes a homogenous muscle group in trained athletes as well as untrained individuals. Specialized long-term training leads to metabolic adaptations in the whole muscle in terms of the biochemical properties, perfusion and composition of fibre types [44]. This metabolic response of the whole muscle has been discussed before in highly trained athletes [5] and surely increases the metabolic potential of the quadriceps.

The muscles of these athletes represent the full range of properties responsible for their extreme performances with untrained individuals somewhere in between of the metabolic extremes. We found no differences in apparent $\mathrm{PCr}$ and $\mathrm{Pi}$ concentration at rest, in line with earlier observations [6] but in contradiction to others [2]. However, we did not attempt a calibrated absolute quantification of resting metabolites, which poses its own technical difficulties [20].

Most historic MRS studies on humans have focused on calf or forearm muscle for practical reasons relating to the bore size. Other things being equal, the larger mass of the quadriceps makes it a better surrogate for whole-body oxidative capacity. Further, it is the main locomotor muscle for untrained people and is used in endurance and sprint athletes during training and competition. Although the methodology and temporal resolution of the FID and spatially resolved CSI spectra are very differ- ent, the implications for $\mathrm{PCr}$ kinetics are in good agreement. There are substantial technical limitations on the acquisition of CSI data with sufficient time resolution for formal fitting of $\mathrm{PCr}$ recovery kinetics.

Taken together, our study nicely shows marked differences regarding high-energy phosphate metabolism and $\mathrm{pH}$ in the muscles of high-performance athletes representing 2 extremes of endurance and sprint performance as well as in untrained individuals assessed by non-invasive in vivo MRS.

\section{Limitations}

$\nabla$

The number of subjects might be a limitation. It is, however, very rare to have subjects at hand that show such a high level of performance in their field. Due to their tight training schedule, these subjects are difficult to recruit for a scientific study. For the same reason we could not obtain a muscle biopsy sample from the athletes to determine their fibre type profile.

\section{Conclusion}

$\nabla$

Our study shows that post-exercise $\mathrm{PCr}$ recovery kinetics are closely related to the physical adaptations and performance level of the population studied, presumably reflecting the higher type I fibre type content and other metabolic adaptations of endurance as compared to sprint training. These changes may be associated with improved exercise efficiency in highly trained athletes if compared to untrained subjects. Furthermore, spatially-resolved data during exercise and recovery show a close similarity between the 4 components of quadriceps within each group, suggesting that the whole muscle functions, at least to a first approximation under these conditions, as a consistent metabolic unit. The results show the suitability of ${ }^{31} \mathrm{P}$ MRS as a way to quantify the divergent metabolic adaptations of sprinttrained and endurance-trained athletes as well as the response of untrained individuals to exercise. ${ }^{31} \mathrm{P}$ MRS qualifies as an alternative, non-invasive tool to study mitochondrial function in different populations.

\section{Acknowledgements \\ $\nabla$}

We would like to thank the athletes and untrained subjects for their kind cooperation and Drs. Stefan Schmid and Michael Fischer for fruitful discussions. This study was funded by the Austrian National Bank (OenB) fund grant 13476. No conflicts of interest are declared.

\footnotetext{
Affiliations

'Department of Radiology, Innsbruck Medical University, Innsbruck, Austria ${ }^{2}$ Department of Sports Science, University of Innsbruck, Innsbruck, Austria ${ }^{3}$ Department of Medical Statistics, Informatics and Health Economics, Innsbruck Medical University, Innsbruck, Austria

${ }^{4}$ Magnetic Resonance and Image Analysis Research Centre (MARIARC) and Department of Musculoskeletal Biology, University of Liverpool, Liverpool, United Kingdom
} 


\section{References}

1 Adhihetty PJ, Irrcher I, Joseph AM, Ljubicic V, Hood DA. Plasticity of skeletal muscle mitochondria in response to contractile activity. Exp Physiol 2003; 88: 99-107

2 Bernus G, Gonzalez de Suso JM, Alonso J, Martin PA, Prat JA, Arus C. 31PMRS of quadriceps reveals quantitative differences between sprinters and long-distance runners. Med Sci Sports Exerc 1993; 25: 479-484

3 Brown TR, Stoyanova R, Greenberg T, Srinivasan R, Murphy-Boesch $J$. NOE enhancements and T1 relaxation times of phosphorylated metabolites in human calf muscle at 1.5 Tesla. Magn Reson Med 1995; 33: 417-421

4 Costill DL, Daniels J, Evans W, Fink W, Krahenbuhl G, Saltin B. Skeletal muscle enzymes and fiber composition in male and female track athletes. J Appl Physiol 1976; 40: 149-154

5 Coyle EF. Improved muscular efficiency displayed as Tour de France champion matures. J Appl Physiol 2005; 98: 2191-2196

6 Crowther GJ, Jubrias SA, Gronka RK, Conley KE. A "functional biopsy" of muscle properties in sprinters and distance runners. Med Sci Sports Exerc 2002; 34: 1719-1724

7 Dash RK, Bell BM, Kushmerick MJ, Vicini P. Estimating in vitro mitochondrial oxygen consumption during muscle contraction and recovery: a novel approach that accounts for diffusion. Ann Biomed Eng 2005; 33: 343-355

8 Dawson B, Fitzsimons M, Green S, Goodman C, Carey M, Cole K. Changes in performance, muscle metabolites, enzymes and fibre types after short sprint training. Eur J Appl Physiol 1998; 78: 163-169

9 Edgerton VR, Smith JL, Simpson DR. Muscle fibre type populations of human leg muscles. Histochem J 1975; 7: 259-266

10 Enoka RM, Stuart DG. Neurobiology of muscle fatigue. J Appl Physiol 1992; 72: 1631-1648

11 Grassi B. Delayed metabolic activation of oxidative phosphorylation in skeletal muscle at exercise onset. Med Sci Sports Exerc 2005; 37: 1567-1573

12 Greenman RL, Smithline HA. The feasibility of measuring phosphocreatine recovery kinetics in muscle using a single-shot ${ }^{31} \mathrm{P}$ RARE MRI sequence. Acad Radiol 2011; 18: 917-923

13 Greiner A, Esterhammer R, Pilav S, Arnold W, Santner W, Neuhauser B, Fraedrich G, Jaschke WR, Schocke MF. High-energy phosphate metabolism in the calf muscle during moderate isotonic exercise under different degrees of cuff compression: a phosphorus 31 magnetic resonance spectroscopy study. J Vasc Surg 2005; 42: 259-267

14 Harriss DJ, Atkinson G. Update - ethical standards in sport and exercise science research. Int J Sports Med 2011; 32: 819-821

15 Haseler LJ, Hogan MC, Richardson RS. Skeletal muscle phosphocreatine recovery in exercise-trained humans is dependent on $\mathrm{O} 2$ availability. J Appl Physiol 1999; 86: 2013-2018

16 Henriksson-Larsen $K B$, Lexell J, Sjostrom M. Distribution of different fibre types in human skeletal muscles. I. Method for the preparation and analysis of cross-sections of whole tibialis anterior. Histochem J 1983; 15: 167-178

17 Hoppeler H, Fluck M. Plasticity of skeletal muscle mitochondria: structure and function. Med Sci Sports Exerc 2003; 35: 95-104

18 Johansen L, Quistorff B. 31P-MRS characterization of sprint and endurance trained athletes. Int J Sports Med 2003; 24: 183-189

19 Kalliokoski KK, Kemppainen J, Larmola K, Takala TO, Peltoniemi P, Oksanen A, Ruotsalainen U, Cobelli C, Knuuti J, Nuutila P. Muscle blood flow and flow heterogeneity during exercise studied with positron emission tomography in humans. Eur J Appl Physiol 2000; 83: 395401

20 Kemp GJ, Meyerspeer M, Moser E. Absolute quantification of phosphorus metabolite concentrations in human muscle in vivo by ${ }^{31} \mathrm{P}$ MRS: a quantitative review. NMR Biomed 2007; 20: 555-565

21 Kemp GJ, Radda GK. Quantitative interpretation of bioenergetic data from ${ }^{31} \mathrm{P}$ and ${ }^{1} \mathrm{H}$ magnetic resonance spectroscopic studies of skeletal muscle: an analytical review. Magn Reson Q 1994; 10: 43-63

22 Kemps HMC, Prompers JJ, Wessels B, Vries WRD, Zonderland ML, Thijssen EJM, Nicolay K, Schep G, Doevendans PAFM. Skeletal muscle metabolic recovery following submaximal exercise in chronic heart failure is limited more by $\mathrm{O}^{2}$ delivery than $\mathrm{O}^{2}$ utilization. Clin Sci (Lond) 2009; 118: 203-210

23 Kent-Braun JA, McCully KK, Chance B. Metabolic effects of training in humans: a ${ }^{31}$ P-MRS study. J Appl Physiol 1990; 69: 1165-1170

24 Korzeniewski B, Zoladz JA. Some factors determining the PCr recovery overshoot in skeletal muscle. Biophys Chem 2005; 116: 129-136
25 Kubukeli ZN, Noakes TD, Dennis SC. Training techniques to improve endurance exercise performances. Sports Med 2002; 32: 489-509

26 Larson-Meyer DE, Newcomer BR, Hunter GR, Joanisse DR, Weinsier RL, Bamman MM. Relation between in vivo and in vitro measurements of skeletal muscle oxidative metabolism. Muscle Nerve 2001; 24: 1665-1676

27 Liu JX, Hoglund AS, Karlsson P, Lindblad J, Qaisar R, Aare S, Bengtsson E, Larsson $L$. Myonuclear domain size and myosin isoform expression in muscle fibres from mammals representing a 100,000-fold difference in body size. Exp Physiol 2009; 94: 117-129

28 Maurer J, Konstanczak P, Sollner O, Ehrenstein T, Knollmann F, Wolff $R$, Vogl TJ, Felix R. Muscle metabolism of professional athletes using ${ }^{31}$ P-spectroscopy. Acta Radiol 1999; 40: 73-77

29 McCully K, Strear C, Prammer M, Leigh J. Recovery of PCr after exercise as an index of oxidative capacity in man. FASEB J 1990; J 4:(A1212)

30 McCully KK, Fielding RA, Evans WJ, Leigh JS Jr, Posner JD. Relationships between in vivo and in vitro measurements of metabolism in young and old human calf muscles. J Appl Physiol 1993; 75: 813-819

31 McCully KK, Vandenborne K, DeMeirleir K, Posner JD, Leigh JS Jr. Muscle metabolism in track athletes, using ${ }^{31} \mathrm{P}$ magnetic resonance spectroscopy. Can J Physiol Pharmacol 1992; 70: 1353-1359

32 Oberbach A, Bossenz Y, Lehmann S, Niebauer J, Adams V, Paschke $R$ Schon MR, Bluher M, Punkt K. Altered fiber distribution and fiberspecific glycolytic and oxidative enzyme activity in skeletal muscle of patients with type 2 diabetes. Diabetes Care 2006; 29: 895-900

33 Petroff OA, Prichard JW, Behar KL, Alger JR, den Hollander JA, Shulman $R G$. Cerebral intracellular $\mathrm{pH}$ by ${ }^{31} \mathrm{P}$ nuclear magnetic resonance spectroscopy. Neurology 1985; 35: 781-788

34 Pette D. Training effects on the contractile apparatus. Acta Physiol Scand 1998; 162: 367-376

35 Pette D, Staron RS. Mammalian skeletal muscle fiber type transitions. Int Rev Cytol 1997; 170: 143-223

36 Putman CT, Xu X, Gillies E, MacLean IM, Bell GJ. Effects of strength, endurance and combined training on myosin heavy chain content and fibre-type distribution in humans. Eur J Appl Physiol 2004; 92: 376-384

37 R Development Core Team. Foundation for Statistical Computing V, Austria. R: A language and environment for statistical computing. 2012; DOI:R foundation for statistical computing, Vienna, Austria.

38 Rittweger J, di Prampero PE, Maffulli N, Narici MV. Sprint and endurance power and ageing: an analysis of master athletic world records. Proc Biol Sci 2009; 276: 683-689

39 Rosser BW, Dean MS, Bandman E. Myonuclear domain size varies along the lengths of maturing skeletal muscle fibers. Int J Develop Biol 2002; 46: 747-754

40 Staron RS, Hagerman FC, Hikida RS, Murray TF, Hostler DP, Crill MT, Ragg KE, Toma K. Fiber type composition of the vastus lateralis muscle of young men and women. J Histochem Cytochem 2000; 48: 623-629

41 Takada S, Okita K, Suga T, Omokawa M, Morita N, Horiuchi M, Kadoguchi T, Takahashi M, Hirabayashi K, Yokota T, Kinugawa S, Tsutsui $H$. Blood flow restriction exercise in sprinters and endurance runners. Med Sci Sports Exerc 2012; 44: 413-419

42 Takahashi H, Inaki M, Fujimoto K, Katsuta S, Anno I, Niitsu M, Itai Y. Control of the rate of phosphocreatine resynthesis after exercise in trained and untrained human quadriceps muscles. Eur J Appl Physiol 1995; 71: 396-404

43 Tanaka $H$, Swensen $T$. Impact of resistance training on endurance performance. A new form of cross-training? Sports Med 1998; 25: 191-200

44 Tesch PA, Karlsson J. Muscle fiber types and size in trained and untrained muscles of elite athletes. J Appl Physiol 1985; 59: 17161720

45 Thompson CH, Kemp GJ, Sanderson AL, Radda GK. Skeletal muscle mitochondrial function studied by kinetic analysis of postexercise phosphocreatine resynthesis. J Appl Physiol 1995; 78: 2131-2139

46 Zawadowska B, Majerczak J, Semik D, Karasinski J, Kolodziejski L, Kilarski WM, Duda K, Zoladz JA. Characteristics of myosin profile in human vastus lateralis muscle in relation to training background. Folia Histochem Cytobiol 2004; 42: 181-190

47 Zoladz JA, Korzeniewski B, Kulinowski P, Zapart-Bukowska J, Majerczak J, Jasinski A. Phosphocreatine recovery overshoot after high intensity exercise in human skeletal muscle is associated with extensive muscle acidification and a significant decrease in phosphorylation potential. J Physiol Sci 2010; 60: 331-341 